DOI:10.18276/sip.2016.45/2-02

\title{
Ewa Drabik*
}

Politechnika Warszawska

\section{O ROLI GIER TOWARZYSKICH W TWORZENIU I ROZWOJU TEORII GIER ORAZ JEJ EKONOMICZNYCH ZASTOSOWAŃ}

\section{Streszczenie}

Teoria gier powstała na początku XX stulecia na bazie gier towarzyskich i hazardowych, takich jak szachy, poker, bakarat, hex czy też jednoręki bandyta. Gry te dały podwaliny do stworzenia interesujących modeli matematycznych (hex), sztucznej inteligencji (hex, szachy), posłużyły do badania złożoności obliczeniowej w różnorodnych zadaniach numerycznych (bakarat), a także do ilustracji wielu dylematów społecznych (dylemat więźnia) oraz problemów, w których zwycięzca bierze wszystko (gra pułkownik Blotto).

Celem pracy jest pokazanie roli gier towarzyskich w powstawaniu modeli matematycznych określonych zjawisk społecznych, ekonomicznych i przyrodniczych oraz ich zastosowań.

Slowa kluczowe: teoria gier, gry z kompletną i niekompletną informacją, gry towarzyskie, gry hazardowe, jednoręki bandyta, szachy

\section{Wstęp}

Gry towarzyskie i hazardowe towarzyszyły ludziom od dawna, gdyż: dostarczały rozrywki, rozpalały emocje i dawały złudną nadzieję na wygraną. Wielu naukowców jest zdania, że zachowania graczy bardzo często ilustrują spontaniczne reakcje uczestników rynku. Hazard to w gruncie rzeczy ciągłe poszukiwanie

* Adres e-mail: ewa.drabik@poczta.fm. 
sposobu na wygraną, które to poszukiwanie samo w sobie jest nagrodą. Przy podejmowaniu decyzji w warunkach wysokiego ryzyka argumenty rozsądku często schodzą na drugi plan. Fakt ten uwzględnia nowoczesna teoria finansów. Szczególną uwagę zwrócono na uczestników rynku, którzy podejmując decyzje w warunkach zwiększonego ryzyka, są dużo częściej podatni na „odruchy stadne” i ataki nieuzasadnionej paniki. Bardzo często zachowują się irracjonalnie.

W kolejnych latach problemy związane z teorią gier stawały się coraz bardziej złożone. W celu ich rozwiązania, a także do opisu całego szeregu zjawisk, które można zaobserwować w naukach społecznych i ekonomicznych, stworzono nowe gry, takie jak: dylemat więźnia (1950 r., M. Flood i E. Dresher dla RAND Corporation), walka płci, gra w tchórza (jej angielska wersja to: chicken), pułkownik Blotto.

Niektóre gry towarzyskie, a także hazardowe, chociażby te oparte na działaniu totalizatora (np. wyścigi konne), nadają się do sprawdzenia całego szeregu mechanizmów rynkowych, takich jak na przykład efektywność rynku czy sprawdzenie zachowań konsumenckich w kontekście docierających informacji na temat określonego towaru.

Celem opracowania jest zaprezentowanie tych gier towarzyskich, których reguły mogą być wykorzystywane w naukach społecznych i przyrodniczych. Przedstawione zostaną również ich ekonomiczne zastosowania.

Układ artykułu przedstawia się następująco. W punkcie pierwszym zaprezentowana została jedna z bardziej znanych gier pozycyjnych, często charakteryzowana jako klasyczna gra różniczkowa, a mianowicie pościg, która została stworzona przez H. Steinhausa. W punkcie drugim pokazano gry pozycyjne z kompletną informacją zwane również grami Banacha-Mazura. Zasady i zastosowania gry Hex zostały omówione w punkcie trzecim. Statystyczne zastosowania reguł jednorękiego bandyty opisano w punkcie czwartym. Punkt piąty został poświęcony bakaratowi, która to gra, podobnie jak szachy, stała się podwaliną sztucznej inteligencji.

\section{Gra pościg, czyli trochę historii}

Jedną z pierwszych prac dotyczącą sytuacji konfliktowych opublikował w 1925 roku Steinhaus. Opracowanie zatytułowane Definicje potrzebne do teorii gry i pościgu ukazało się w studenckim czasopiśmie „Myśl Akademicka” we Lwowie. Po wojnie było nieosiągalne. W roku 1957 profesor K. Ajdukiewicz przywiózł 
egzemplarz z biblioteki Uniwersytetu Lwowskiego. W roku 1960 poprzez S. Ulama praca ta, po przetłumaczeniu na język angielski, dotarła do Stanów Zjednoczonych i została tam opublikowana w piśmie zajmującym się sprawami morskimi: „Naval Research Logistics Quaterely". Została poprzedzona wstępem H.W. Kuhna. W tej niewielkiej pracy zostało wprowadzone pojecie strategii, funkcji wypłaty, która charakteryzuje każdą grę, oraz zasada wyboru strategii minimaksowej.

Pisząc to, Steinhaus nie wiedział, że znany francuski matematyk E. Borel parę lat wcześniej $(1921,1926)$ doszedł do podobnych wniosków, wykorzystując w tym celu bakarata, o którym będzie mowa w dalszej części artykułu. W roku 1926 J. von Neumann udowodnił jedno z ważniejszych twierdzeń teorii gier, to jest twierdzenie o minimaksie.

W uproszczeniu można przyjąć, że gracze 1 i 2 wybierają pewne punkty w zbiorach swych strategii: $A$ i $B$. Po niezależnym dokonaniu wyboru przez obydwu graczy odczytuje się wypłatę $\varphi(a, b) a \in A, b \in B$. Jest to kwota, jaką gracz 1 powinien zapłacić graczowi 2. Najbardziej pożądanym dla obydwu graczy wyborem jest zastosowanie takiej strategii, aby:

$$
\inf _{b \in B} \sup _{a \in A} \varphi(a, b)=v=\operatorname{supinf}_{a \in A} \varphi(a, b)
$$

gdzie $v$ jest wartością gry.

Gra spełniająca powyższą równość jest domknięta. Gdy zamiast równości mamy nierówności ostre, to mówimy, że gra jest otwarta, nieostre: domknięto-otwarta. Gra domknięta nazywana jest również grą zdeterminowana.

Twierdzenie o minimaksie stało się częścią ogólniejszego twierdzenie Nasha o istnieniu punktu równowagi w strategiach mieszanych. Od tego czasu teoria gier bardzo się rozwinęła i stosowana jest przede wszystkim w naukach społecznych i przyrodniczych.

Wracając do pracy Steinhausa z roku 1925 dotyczącej pościgu, warto dodać, że opisał on w niej typową grę pozycyjną (gry pozycyjne to np. szachy, warcaby, poker). Tego rodzaju gry polegają na tym, że toczą się w sposób sekwencyjny, według z góry ustalonych reguł. Wariantem gier pozycyjnych są wspomniane gry pościgowe.

Przykład 1. Gra pościgowa. Pies biega po ulicy wzdłuż sztachet, chcąc zbliżyć się jak najbardziej do królika, a królik chce stanąć jak najdalej od szczekającego psa. Możliwe są również inne warianty tej gry, na przykład ścigające się statki o różnych gabarytach. Strategią jest pewne równanie różniczkowe - przepis, który na podstawie aktualnych położeń obu statków wskazuje kierunek pościgu (strategia dla ścigającego) lub kierunek ucieczki (strategia dla ściganego). Reguły tej gry to 
podanie prawych stron odpowiednich równań. Czas, po którym nastąpi schwytanie, jest funkcją tych strategii.

Gry pościgowe są ciągłym wariantem gier pozycyjnych, którym poświęcony jest kolejny punkt.

\section{Gry pozycyjne}

Grami pozycyjnymi są między innymi gry typu Banacha-Mazura (zob. Mycielski, 1992), które po raz pierwszy zostały przedstawione w Księdze Szkockiej około 1934 roku (Mauldin, 1981). Oto typowa gra typu Banacha-Mazura.

Przykład 2. Gracz 1 wybiera cyfrę 0 lub 1, a następnie drugi gracz wybiera jedną z nich, wiedząc, jaki był wybór przeciwnika. Po przeliczalnej liczbie kroków powstaje pewien ciąg zer i jedynek. Ciągi tego typu tworzą zbiór nazywany zbiorem Cantora $C$. Jeżeli w zbiorze Cantora wyróżniamy pewien podzbiór $P \subset C$, to gracz 1 gra na ten zbiór, to znaczy jeżeli podana liczba znajduje się $\mathrm{w}$ tym zbiorze, to wygrywa gracz 1 .

Korzystając z pewnika wyboru (axiom of choice), pokazano, że istnieją takie zbiory $P$, dla których żaden z graczy nie ma strategii gwarantującej mu wygraną. Wprowadzenie w 1960 roku aksjomatu determinacji przez H. Steinhausa i J. Mycielskiego pozwoliło ustalić klasę zbiorów (w uproszczeniu - przeliczalne rodziny podzbiorów liczb rzeczywistych), dla których gra typu Banacha-Mazura ma strategię zwycięską.

Formalnie grę pozycyjną definiuje się w następujący sposób.

Niech $A$ i $B$ będą odpowiednio zbiorami strategii gracza 1 i gracza 2; $\varphi: A \times B \rightarrow \bar{\Re}$ oznacza funkcję wypłaty, przy czym $\bar{\Re}=\Re \cup\{-\infty,+\infty\}$ (gdzie $\Re$ jest zbiorem liczb rzeczywistych). W rozdziale 2 trójkę $\langle A, B, \varphi\rangle$ nazwaliśmy grą.

Reguły naszej gry określamy w sposób następujący: gracz 1 wybiera strategię $a \in A$, gracz 2 wybiera strategię $b \in B$. Wybory są niezależne. Zakładamy, że każdy z graczy ma informacje o dotychczasowych ruchach przeciwnika. W przypadku wygranej gracza 1 , gracz 2 płaci kwotę $\varphi(a, b)$. W przeciwnym razie gracz 1 płaci drugiemu: $\varphi(a, b)$.

Niech $\omega \in N$. Przez $P$ oznaczmy zbiór wyborów dla obydwu graczy. Gracz 1 wybiera $p_{0} \in P$, gracz $2 p \in P$, następnie gracz 1 wybiera $p_{2} \in P$ itd. Istnieje funkcja $f: P^{\omega} \rightarrow \bar{\Re}, f\left(p_{0}, p_{1}, \ldots\right)$ określająca symboliczną wypłatę, jaką gracz 2 wypłaca graczowi $1 \mathrm{w}$ przypadku przegranej. 
Definicja 1. Trójkę $\langle A, B, \varphi\rangle$ taką, że

$A=\left\{a: \bigcup_{n<\omega} P^{n} \rightarrow P\right\}$, gdzie $P^{0}=\{\phi\}$,

$B=\left\{b: \bigcup_{0<n<\omega} P^{n} \rightarrow P\right\}$,

$\varphi(a, b)=f\left(p_{0}, p_{1}, \ldots\right)$, przy założeniu, że istnieje funkcja $f: P^{\omega} \rightarrow \bar{\Re}$ oraz

$p_{0}=a(\phi), p_{1}=b\left(p_{0}\right), p_{2}=a\left(p_{1}\right), p_{3}=b\left(p_{0}, p_{2}\right), p_{4}=a\left(p_{1}, p_{3}\right) \ldots$

nazywamy gra z petna informacja (perfect information - PI game) w postaci strategicznej.

Definicja 2. (Mycielski, 1992). Grę $\langle A, B, \varphi\rangle$ nazywamy zdeterminowana, jeżeli spełnia równość (1).

Gra nie jest zdeterminowana, jeżeli $\inf _{b \in B} \sup _{a \in A} \varphi(a, b)<v<\operatorname{supinf}_{a \in A} \varphi(a, b)$.

Twierdzenie 1. (Mycielski, 1992). Każda skończona gra pozycyjna ma wartość.

Dowód (Mycielski, 1992).

Bezpośrednią konsekwencją twierdzenia 1 jest fakt, że jeżeli gra ma wartość, to jest zdeterminowana. Najbardziej znaną grą pozycyjną z kompletną informacją są szachy, której reguły znalazły cały szereg zastosowań, zwłaszcza przy tworzeniu sztucznej inteligencji (Drabik, 2014).

\section{Hex jako typowa gra pozycyjna}

Hex jest grą opracowaną współcześnie przez duńskiego poetę i inżyniera P. Heina w roku 1942, zwaną inaczej grą „Polygon”. W 1948 roku grę ponownie rozpatrzył J. Nash z Princeton University, późniejszy laureat Nagrody Nobla (1994). Wykorzystywana jest w niej specjalna plansza oraz 122 pionki (61 białych i 61 czarnych). Zasady gry są następujące. Grę rozpoczyna grający pionkami białymi. Gracze na zmianę wykonują kolejne ruchy, które polegają na dostawianiu na planszę coraz to nowych pionków. Pionek raz postawiony nie wykonuje żadnych ruchów, nie zmienia także położenia. Pionki nie „biją” się wzajemnie. Wygrywa więc ten z graczy, któremu uda się utworzyć łańcuch swoich pionków (zająć swymi pionkami kolejne sąsiadujące ze sobą pola) łączący dwa brzegi planszy (biały z białym, czarny z czarnym). Cztery narożne pola planszy uważa się za należące zarówno do brzegów białych, jak i czarnych. 
Hex jest więc typową grą sekwencyjną z kompletną informacja (PI game), która doczekała się uogólnienia, a tym samym modelu. Będąc grą o skończonej liczbie strategii, jest zatem zdeterminowana (zob. Mycielski, 1992). Tak więc jeden z graczy (zazwyczaj wykonujący pierwszy ruch) ma strategię zwycięską. Słuszne jest następujące twierdzenie.

Twierdzenie 2. (i) Kiedy cała plansza zapełni się pionkami, to zawsze jeden z graczy przegrywa.

(i) Biały ma strategię wygrywającą.

Dowód (Mycielski, 1992).

Formalny opis gry hex może być następujący.

Niech $G$ będzie grafem zdefiniowanym jako trójka $(P, Q, I)$, gdzie $P, Q$ są skończonymi rozłącznymi zbiorami i $E \subseteq((P \times Q) \cup(Q \times P))$, I będzie zbiorem strzałek. Zakłada się, że dla każdej pary $(a, b) \in E$ istnieje $c$ takie, że $(b, c) \in E$. Funkcja $\varphi: E \rightarrow R$ jest dana oraz punkt $p_{\text {first }} \subseteq P$ jest stały. Gracze 1 i 2 kolejno wykonują ruchy: $p_{0}=p_{\text {first }}, q_{0} \in Q, p_{1} \in P, q_{1} \in Q, \ldots$ takie, że $\left(p_{i}, q_{i}\right) \in E$ i $\left(q_{i}, p_{i+1}\right) \in E$. Możliwe są trzy wersje tej gry.

$\mathrm{G}_{1}$ : gracz 2 płaci graczowi 1 następującą wypłatę:

$$
\limsup _{n \rightarrow \infty} \frac{1}{2 n} \sum_{i=0}^{n-1}\left(\varphi\left(p_{i}, q_{i}\right)+\varphi\left(q_{i}, p_{i+1}\right)\right)
$$

$\mathrm{G}_{2}$ : gracz 2 płaci graczowi 1 następującą wypłatę:

$$
\liminf _{n \rightarrow \infty} \frac{1}{2 n} \sum_{i=0}^{n-1}\left(\varphi\left(p_{i}, q_{i}\right)+\varphi\left(q_{i}, p_{i+1}\right)\right)
$$

$\mathrm{G}_{3}$ : gra kończy się po wykonaniu ruchów $p_{n} \in\left\{p_{0}, . ., p_{n-1}\right\}$ przez gracza 1 lub $q_{n} \in\left\{q_{0}, . ., q_{n-1}\right\}$ przez gracza 2 (np. w przypadku gracza 1 pętla $p_{n}=p_{m}$ dla $m<n$ ). Gracz 2 płaci graczowi 1 następującą wypłatę:

$$
v=\frac{1}{2(n-m)} \sum_{i=0}^{n-1}\left(\varphi\left(q_{i}, p_{i+1}\right)+\varphi\left(p_{i+1}, q_{i+1}\right)\right)
$$

Uwaga. Nieskończone gry $\mathrm{G}_{1}$ i $\mathrm{G}_{2}$ są zdeterminowane, bo mają taką samą wartość jak gra skończona $\mathrm{G}_{3}$. 


\section{Asymptotycznie efektywna reguła alokacji a problem jednorękiego bandyty}

Jednoręki bandyta jest maszyną mechaniczną lub elektroniczną wyposażoną najczęściej w trzy bębny z zawieszonymi na nich obrazkami, przeznaczoną do gier hazardowych. Różne układy na bębnie oznaczają różne wygrane lub przegrane. Ta prosta maszyna znana jest od 1887 roku, kiedy to niejaki Ch. Frey skonstruował ją do uatrakcyjnienia sprzedaży oferowanych produktów. Maszyny te odniosły wielki sukces. W połowie XX wieku mechaniczne konstrukcje zostały zastąpione skomputeryzowanymi i wstawione do kasyn gry. Miały one zapewnić rozrywkę paniom, których mężowie i narzeczeni oddawali się „męskim” grom karcianym. Pierwsze automaty Freya były w pełni losowe. Obecnie z powodu zastosowanego oprogramowania losowość jest niepełna. Problemem generowania wygranych (strat) i uczestnictwa w takich grach zainteresowali się naukowcy, którzy zajęli się przede wszystkim opracowywaniem strategii maksymalizujących zyski (minimalizujących straty). Strategie te znalazły zastosowanie w wielu dziedzinach wiedzy, takich jak: ekonomia, biologia, teoria podejmowania decyzji. Jedną z nich, stosowaną w różnego rodzaju metodach, można opisać w sposób podany poniżej (Lai, Robbins, 1985).

„Zaadoptowany” przez badaczy problem decyzyjny generalnie polega na tym, że na podstawie obserwacji wyników gry gracz podejmuje decyzję, czy w konkretnej fazie będzie grał, czy też nie, zaś jego celem jest maksymalizacja całkowitej (lub średniej) wygranej.

Zakłada się, że $w_{i}(i=1,2, \ldots)$ oznacza odpowiednią stratę lub zysk w $i$-tej fazie dowolnej gry rozgrywanej wielokrotnie (niekoniecznie jednorękiego bandyty). Niech $f\left(w, \theta_{i}\right)$ będzie funkcją gęstości dla $w$ odpowiadającą pewnej mierze probabilistycznej $v$, gdzie funkcja $f(.,$.$) jest znana, zaś \theta_{i}$ są nieznanymi parametrami należącymi do pewnej przestrzeni $\Theta$. Zakłada się również, że spełniony jest warunek

$$
\int_{-\infty}^{\infty}|w| f(w, \theta) d v(w)<\infty \text { dla każdego } \theta \in \Theta .
$$

W trakcie gry sekwencyjnie zbierane są informacje dotyczące przeszłych zysków i strat $w_{l}, w_{2}$. Innymi słowy, zbierane są dane historyczne, na podstawie których podejmowane są decyzje dotyczące uczestnictwa w kolejnej fazie gry. Regułę gry $\varphi$ można traktować jako ciąg zmiennych losowych $\varphi_{1}, \varphi_{2}, \ldots$, przy czym $\varphi_{t}=0$, kiedy gracz rezygnuje z gry, $\varphi_{t}=1$, kiedy gracz decyduje się na kontynuację gry. W każdej z faz obliczane są statystyki $\mu_{t}, U_{t}$ odpowiadające ,średnim” zyskom i stratom. Własności tych statystyk zostały zaprezentowane w pracy (Lai, Robbins, 1985). 
Niech $S_{n}=w_{1}+\ldots+w_{n}$. Celem gracza jest osiągniecie największej z możliwych oczekiwanej wartości sumy wygranych $S_{n}$ przy $n \rightarrow \infty$. Niech

$$
\mu(\theta)=\int_{-\infty}^{+\infty} w f(w ; \theta) d v(w)
$$

będzie oczekiwaną wypłatą w grze. Oczekiwaną sumę wypłat $S_{n}$ w grze do fazy $n$ można zapisać następująco:

$$
E S_{n}=\sum_{j=0}^{1} \sum_{i=1}^{n} E\left(w_{i} I_{\left\{\varphi_{i}=j\right\}} \mid \mathfrak{I}_{i-1}\right)=\sum_{j=0}^{1} \mu(\theta) T_{n}(j)
$$

gdzie

$T_{n}(j)=\sum_{i=1}^{n} I_{\left\{\varphi_{i}=j\right\}}(j=0,1)$ jest liczbą momentów, podczas których gracz prowadził grę do fazy $n$ (jeśli $j=1)$, lub też liczbą momentów, podczas których gracz zrezygnował z gry do fazy $n$ (jeśli $j=0$ );

$I_{\{, j}$ jest indykatorem zdarzenia.

Zdarzenie $\left\{\varphi_{n}=j\right\}$ należy do $\sigma$ - ciała $\mathfrak{I}_{\mathrm{n}-1}$ generowanego przez poprzednie wartości $\varphi_{1}, w_{2}, \ldots, \varphi_{n-l}, w_{n-l}$.

Problem maksymalizacji $E S_{n}$ jest równoważny minimalizacji następującego kosztu gry

$$
R_{n}(\theta)=n \mu^{*}-E S_{n}=\sum_{j: \mu\left(\theta_{j}\right)<\mu^{*}}\left(\mu^{*}-\mu\left(\theta_{j}\right)\right) E T_{n}(j)
$$

gdzie:

$\mu^{*}=\max \left\{\mu\left(\theta_{0}\right), \mu\left(\theta_{1}\right)\right\}=\mu\left(\theta^{*}\right)$ dla $\theta^{*} \in\left\{\theta_{0}, \theta_{1}\right\}$.

Pomocniczo wprowadza się tak zwaną liczbę Kulbacka-Leiblera $I(\theta, \lambda)$, którą określa się za pomocą formuły:

$$
I(\theta, \lambda)=\int_{-\infty}^{\infty} \log \frac{f(w ; \theta)}{f(w ; \lambda)} \cdot f(w ; \theta) d v(w)
$$

przy czym $0<I(\theta, \lambda)<\infty$, jeżeli $\mu(\lambda)>\mu(\theta)$.

Lai i Robbins (1985, s. 7, Twierdzenie 1) pokazali, że koszt wyrażony za pomocą formuły (7) można przedstawić jako:

$$
R_{n}(\theta) \approx\left\{\sum_{j: \mu\left(\theta_{j}\right) \mu^{*}}\left(\mu^{*}-\mu\left(\theta_{j}\right)\right) / I\left(\theta_{j}, \theta^{*}\right)\right\} \log n \text { przy } n \rightarrow \infty
$$

Ponadto, we wspomnianej pracy pokazano również, że $R_{n}(\theta)$ przy $n \rightarrow \infty$ zbiega do asymptoty (jest zbieżny asymptotycznie). Skonstruowano także regułę gry $\varphi$ minimalizującą $R_{\mathrm{n}}(\theta)$, którą następnie nazwano asymptotycznie efektywna reguła alokacji (asymptotically efficient allocation rule). Zostanie ona zaprezentowana poniżej 
w odniesieniu do zysków i strat pewnej gry. Wcześniej jednak omówione zostaną własności, które powinny spełniać statystyki pomocnicze $\mu_{n}, U_{n}$, które wykorzystywane są przy konstrukcji strategii $\varphi$. Podany będzie także przykład, który zilustruje, jaką postać przyjmują te statystyki, oraz liczba Kulbacka-Leiblera dla konkretnego rozkładu $f(.$, ), na przykład normalnego.

Niech $w_{1}, w_{2}, \ldots$ będą niezależnymi zmiennymi losowymi o jednakowym rozkładzie o funkcji gęstości $f(w ; \theta)$ z odpowiadającą miarą probabilistyczną $v$, gdzie $\theta \in \Theta$ oznacza nieznany parametr. Górną granicę przedziału ufności dla nieznanej średniej $\mu(\theta)$ można zdefiniować za pomocą funkcji $g_{n t}: \Re^{t} \rightarrow \Re(n=1,2, \ldots ; t=1$, $\ldots, n)$, która to funkcja dla każdego $\theta \in \Theta$ spełnia następujące warunki.

(W1) $P_{\theta}\left\{r \leq g_{n t}\left(w_{1}, \ldots, w_{t}\right)\right.$ dla wszystkich $\left.t \leq n\right\}=1-o\left(n^{-1}\right)$ dla każdego $r<\mu(\theta)$ gdzie $o\left(n^{-1}\right)$ jest pewną małą wartością zależną od $1 / n$ przy $n \rightarrow \theta$.

(W2) $\lim _{\varepsilon \rightarrow 0}\left(\limsup _{n \rightarrow \infty} \sum_{t=1}^{n} P_{\theta}\left\{g_{n t}\left(w_{1}, \ldots, w_{t}\right) \geq \mu(\lambda)-\varepsilon\right\} / \log n\right) \leq 1 / I(\theta, \lambda)$, jeżeli $\mu(\lambda)>\mu(\theta)$.

(W3) $g_{n t}$ jest funkcją niemalejącą, gdy $n \geq t$ dla każdego $t=1,2, \ldots$

Dodatkowo definiuje się estymator punktowy $h_{t}\left(w_{l}, \ldots, w_{t}\right)$ dla średniej $\mu(\theta)$, $h_{t}: \Re^{t} \rightarrow \Re$. Spełnia on warunki

(W4) $h_{t} \leq g_{n t}$ dla każdego $\theta \in \Theta$.

(W5) $P_{\theta}\left\{\max _{t}\left|h_{t}\left(w_{1}, \ldots, w_{t}\right)-\mu(\theta)\right|>\varepsilon\right\}=o\left(n^{-1}\right)$ dla każdego $\varepsilon>0$.

Można zauważyć, że warunek W5 jest spełniony dla średniej, to jest dla $h_{t}\left(w_{1}, \ldots, w_{t}\right)=\left(w_{1}+\ldots+w_{t}\right) / t$, gdy $E_{\theta} w_{i}^{2}<\infty \quad(i=1, \ldots, t)$.

Przykład. Przyjmijmy, że $w_{\mathrm{i}}(i=1,2, \ldots)$ będą niezależnymi zmiennymi losowymi o rozkładzie normalnym i znanej wariancji $\sigma^{2}>0$ oraz nieznanej wartości oczekiwanej $E w_{i}=\theta, \mu(\theta)=\theta, \theta=(-\infty, \infty), v-$ jest miarą Lesbegu'e. Funkcja gęstości jest postaci:

$$
z(w ; \theta)=\left(2 \pi \sigma^{2}\right)^{-1 / 2} \exp \left\{-\frac{(w-\theta)^{2}}{2 \sigma^{2}}\right\} .
$$

Z prostych obliczeń wynika, że liczba Kulbacka-Leiblera przyjmuje postać:

$$
I(\theta, \lambda)=\frac{(\theta-\lambda)^{2}}{2 \sigma^{2}} .
$$

Po podstawieniu $I(\theta, \lambda)$ do wzoru (9) i dokonaniu odpowiednich przekształceń otrzymujemy równość:

$$
\lim _{n \rightarrow \infty} n^{-1} E S_{n}=\mu^{*} .
$$


A zatem średnia wypłata na jednostkę czasu może być równa oczekiwanej wypłacie $\mathrm{w}$ dowolnej $\mathrm{z}$ faz gry. Estymator punktowy $h_{t}\left(w_{1}, \ldots, w_{t}\right) \mathrm{w}$ tym przypadku odpowiada średniej

$$
h_{t}\left(w_{1}, \ldots, w_{t}\right)=\left(w_{1}+\ldots+w_{t}\right) / t=\bar{w}_{t} .
$$

Z kolei górną granicę przedziału ufności dla średniej można wyrazić za pomocą formuły:

$$
g_{n t}\left(w_{1}, \ldots, w_{t}\right)=\bar{w}_{t}+\sigma\left(2 a_{n t}\right)^{1 / 2} \text { dla } n \geq t,
$$

gdzie $\sigma$ jest odchyleniem standardowym, $a_{\mathrm{nt}}(n=1,2, \ldots ; t=1, \ldots, n)$ jest dodatnią stałą taką, że dla każdego $t, a_{\mathrm{nt}}$ jest niemalejąca dla $n \geq t$

oraz istnieje $\varepsilon \rightarrow 0$ takie, że spełniona jest nierówność

$$
\left|a_{n t}-\frac{\log n}{t}\right| \leq \frac{\varepsilon(\log n)^{1 / 2}}{t^{1 / 2}} \text { dla każdego } t \leq n .
$$

Analiza dotycząca innych niż normalny rozkładów funkcji $f(.,$.$) została zapre-$ zentowana w pracy (Lai, Robbins, 1985).

Niech $w_{1}, \ldots, w_{T_{n}(j)}$ oznacza sukcesywne obserwacje zysków i strat do fazy $n$. Należy zauważyć, że $T_{n}(0)+T_{n}(1)=n$, przy czym $T_{n}(0)$ oznacza liczbę chwil do fazy $n$, podczas których gracz zgodnie ze strategią nie uczestniczył w grze, zaś $T_{n}(1)$ oznacza liczbę chwil do fazy $n$, podczas których gracz prowadził grę.

Wspomniane wcześniej statystyki pomocnicze to

$$
\mu_{n}(j)=h_{T_{n}(j)}\left(w_{1}, \ldots, w_{T_{n}(j)}\right), U_{n}(j)=h_{T_{n}(j)}\left(w_{1}, \ldots+w_{T_{n}(j)}\right) .
$$

Strategia gry $\varphi$ jest następująca:

1. Przez dwie pierwsze fazy gry gracz prowadzi grę i zbiera informacje o wygranych lub stratach $w_{1}, w_{2}$.

2. W fazie $(n+1)(n \geq 2)$ gracz podejmuje decyzję dotyczącą dalszej gry: $\varphi_{n+1}=1$ decyduje się na grę, $\varphi_{n+1}=0$ rezygnuje $\mathrm{z}$ gry.

a) jeżeli $\mu_{n} \leq U_{n}$, to $\varphi_{n+1}=1$,

b) jeżeli $\mu_{n}>U_{n}$, to $\varphi_{n+1}=0$.

Strategia $\varphi$ jest asymptotycznie efektywna, co oznacza, że koszt takiej gry przy $n \rightarrow \infty$ zbiega do asymptoty. Jest to szczególnie ważne, gdy udział w grze jest obowiązkowy, a można jedynie zrezygnować z uczestnictwa w pojedynczych fazach gry.

Powyższą strategię można wykorzystać do gry na giełdzie papierów wartościowych, „manewrując” $k \geq 1$ akcjami spółek (akcje odpowiadały $k$ ramionom). Przeprowadzone symulacje komputerowe dla giełd: NYSE (New York Stock Exchange) oraz Giełdy Papierów Wartościowych w Warszawie pokazały, że w dłuż- 
szym okresie czasu po przetestowaniu akcji dużej liczby spółek oraz uwzględnieniu kosztów transakcji należałoby raczej zrezygnować z dywersyfikacji portfela (przy dużym $n$ ) i zdecydować się na grę akcjami niewielkiej liczby spółek przynoszących w dłuższym horyzoncie czasowym najwyższe dochody. Szczegółowe badania pokazały, że czasami najlepiej, aby była to jedna spółka (Drabik, 2000).

\section{Bakarat jako gra dająca początek sztucznej inteligencji}

Gra karciana bakarat odegrała kluczową rolę w tworzeniu zarówno teorii gier, jak i sztucznej inteligencji. Już w XIX wieku matematyk A.W.R. Bertrand (1889) analizował strategiczne posunięcia w tej grze. Jej regułami interesował się również inny matematyk - E. Borel (1920). Zasady bakarata w wersji klasycznej są następujące. Dziesiątki i figury liczą się jako 0 , as jako 1, natomiast pozostałe karty mają taką samą wartość, jaką sobą reprezentują. Podczas gry rozdaje się po dwie karty. Jeżeli gracz osiągnie naturalną rękę, to znaczy suma kart jest równa 8 lub 9, to ta osoba wygrywa. Najsilniejszym zestawem kart jest 9; jeżeli sumy kart gracza i krupiera są równe, mamy remis. W przypadku, gdy gracz i krupier nie mają zestawu, tak zwanej naturalnej ręki, gra przechodzi do gracza. W momencie, gdy któryś z uczestników gry będzie miał na przykład karty 7 i 9, wynikiem tego rozkładu jest liczba 6 $(7+9=16)$, czyli ostatnia cyfra sumy. Na przykład suma kart równa 10 będzie miała wynik równy 0 . Jeżeli wynik dwóch pierwszych kart gracza jest mniejszy od 6, wówczas gracz dobiera kolejną kartę, dzięki czemu uzyskuje nowy wynik. Jeżeli wynik gracza to 6 lub 7 - gracz nie dobiera żadnej karty; jego wynik zatrzymuje się właśnie na tej liczbie. W przypadku, gdy gracz pozostaje z wynikiem 6 lub 7, nie dobierając żadnej karty, następuje kolej krupiera. Musi on dobrać karty w przypadku, jeżeli suma kart jest mniejsza od 6, lub pozostać przy swojej ręce, gdy wynik wynosi 6 lub 7.

Prawdopodobieństwo, że dwie karty mają wartość 0 , wynosi: $\left(\frac{4}{13}\right)^{2}+9\left(\frac{1}{13}\right)^{2}=\frac{25}{169}$. Prawdopodobieństwo, że dwie karty mają wartość $i \in\{1,2, \ldots, 9\}$, wynosi: $\frac{4}{13} \cdot \frac{1}{13}+\frac{1}{13} \cdot \frac{4}{13}+8\left(\frac{1}{13}\right)^{2}=\frac{16}{169}$.

Grę bakarat można przedstawić jako klasyczną grę dwumacierzową $(X, Y)$, gdzie $X$ jest macierzą złożoną z kolejnych wartości dwóch kart gracza, $Y$ jest macierzą złożoną z możliwych wartości dwóch kart krupiera. Szczegółowe badania nad zbiorami możliwych strategii dla gracza i krupiera prowadził S.N. Ethier (2010). Stwierdził on, że macierze gry mogą mieć wymiar $2 \times 2^{88}$. Pomimo „mnogości” 
rozgrywek możliwe jest wyznaczenie strategii w równowadze Nasha i jest ich kilka. Zaprezentował trzy główne algorytmy prowadzące do równowagi Nasha i zasugerował, iż jest możliwe ich wykorzystanie do zmniejszenia wysokości należnych podatków przy planowaniu niektórych inwestycji itp.

Bakarat podobnie jak szachy dał podstawy do tworzenia sztucznej inteligencji.

\section{Podsumowanie}

Metody rozumowania oparte na teorii gier wykorzystywane są również podczas badania stanów równowagi w wielu zagadnieniach ekonomicznych. W tym przypadku równowaga suboptymalna (czyli najlepsza dla poszczególnych graczy) zastępowana jest przez równowagę ogólną w sensie Nasha. Inaczej rzecz ujmując, jeżeli poszczególni gracze zrezygnują z dostępnych im, ale globalnie niepożądanych sposobów postępowania, na przykład przez subsydiowanie inwestycji, które z punktu widzenia poszczególnych graczy wydają się nieuzasadnione, lub konsumpcji koniecznej, to mogą oni osiągnąć stan równowagi globalnej (w sensie Nasha). Już od czasów J.M. Keynesa próbowano dokonywać takich manewrów poprzez przesuwanie punktów równowagi ekonomicznej, a więc zwiększanie produkcji, podnoszenie popytu, obniżanie opodatkowania, podwyższanie świadczeń emerytalnych, zachęcanie do prywatnych i publicznych inwestycji za pomocą gwarancji i innych rabatów udzielanych podmiotom gospodarczym, budowy dróg i urządzeń komunalnych itp.

Gry towarzyskie stanowią także znakomitą bazę do tworzenia adekwatnych modeli matematycznych (hex), algorytmów związanych ze sztuczną inteligencją (szachy), teoretycznej analizy złożoności obliczeniowej szeregu problemów numerycznych (bakarat). Mogą też być ilustracją całego szeregu problemów ekonomicznych, zwłaszcza takich, w których zwycięzca bierze wszystko (pułkownik Blotto).

\section{Literatura}

Drabik, E. (2000). Zastosowania teorii gier do inwestowania w papiery wartościowe. Białystok: Wyd. Uniwersytetu w Białymstoku.

Drabik, E. (2014). On Positional Games with Perfect Information and Their Applications. Economic World, 2, 3, 180-187.

Ethier, S.N. (2010). The Doctrine of Chances: Probabilistic Aspects of Gambling. BerlinHeidelberg: Springer Verlag. 
Lai, T.L., Robbins, H. (1985). Asymptotically Efficient Adaptive Allocation Rules. Advanced in Applied Mathematics, 6, 4-22.

Mauldin, R.D. (1981). The Scottish Book. Mathematics from the Scottish Cafe. BostonBasel-Stuttgart: Birkhausen.

Mycielski, J. (1992). Games with Perfect Information. W: R.J. Aumann, S. Hart (red.), Handbook of Game theory with Economic Application (s. 20-40). T. 1. Amsterdam: North - Holland,

Palacios Huerta, I., Serrano, R. (2006). Rejecting Small Gambles Under Expected Utility. Economics Letters, 91, 250-259.

Ryll-Nardzewski, C. (1973). Prace Hugona Steinhausa o sytuacjach konfliktowych. Wiadomości Matematyczne, XVII, 29-39.

Tversky, A., Kahneman, R. (1991). Loss Aversion Riskless Choice of Reference - Dependent Model. Quarterly Journal of Economic, 106, 204-217.

\title{
ON THE ROLE OF THE SOCIAL GAMES IN CREATION AND DEVELOPMENT OF GAME THEORY, STATISTICS AND ITS APPLICATIONS
}

\begin{abstract}
The game theory was created at the beginning of the $20^{\text {th }}$ century upon the basis of social as well as gambling games, such as chess, poker, baccarat, hex or one-armed bandit. The aforementioned games lay solid foundations for analogical mathematical models (e.g. hex), artificial intelligence algorithms (hex), theoretical analysis of computational complexity attributable to various numerical problems (baccarat), as well as for illustration of several economic dilemmas - particularly in the case where the winner takes everything (e.g. noughts and crosses).

The aim of the paper is to discuss these social games along with their potential mathematical models which are governed by the rules predominantly applicable to the social and natural sciences.
\end{abstract}

Translated by Ewa Drabik

Keywords: game theory, games with perfect and imperfect information, social games, gambling games, one-armed bandit, chess

JEL Code: C72 
